\title{
Diversidad y sentido patrimonial: contribuciones desde la antropología del territorio al estudio de comunidades tradicionales ${ }^{1}$
}

\section{Diversity and the sense of heritage: a contribuition based on the anthropological perspective on territory for the study of traditional communities}

\author{
Francisco Ther Ríos \\ Universidad de Los Lagos
}

\begin{abstract}
Resumen: Considerando la complejidad socioambiental, es importante diseñar y poner a prueba, estrategias teórico-metodológicas que posibiliten investigaciones a nivel local, sin olvidar las interlocuciones con lo global. Este trabajo pretende contribuir desde la Antropología del Territorio al estudio de los procesos territoriales locales donde participan comunidades tradicionales. El objetivo del artículo es, por lo tanto, aportar al estudio interdisciplinario de comunidades tradicionales, subrayándose dos aspectos: a) la necesidad de investigar la diversidad existente en el interior de las comunidades tradicionales; b) la necesidad de poner valor a conocimientos y saberes de actores diversos por medio de la noción de "sentido patrimonial"; con lo cual se intenta contribuir con la mejora del mundo para "ganarnos nuestro futuro".
\end{abstract}

Palabras clave: Complejidad territorial. Interdisciplina. Sustentabilidad. Territorios vividos/ territorios normados. Sentido patrimonial.

\begin{abstract}
When investigating socio-environmental complexities, it seems important to develop and test theoretical-methodological strategies that allow for local investigations without disregarding linkages to global aspects. This research is an attempt to contribute, from an anthropological perspective on the territory, to the study of local territorial processes in which local communities are involved. Therefore, its main objective is to add to the interdisciplinary study of traditional communities highlighting especially the following aspects: a) the need to investigate the internal differences in traditional communities, b) the need to re-evaluate the knowledge and traditional wisdom of different actors based on the concept of the "sense of heritage". Thus, an attempt is made to regain a new enchantment of the world to "construct our future".
\end{abstract}

Keywords: Territorial complexity. Interdisciplinarity. Sustainability. Lived/ normatized territories. Sense of heritage.

${ }^{1}$ Este trabajo es resultado del Proyecto FONDECYT 1080665 “Las sociedades litorales como sistemas de prácticas y saberes tradicionales y científicos: la caleta como modelo de imaginarios pesqueros y dinámicas de uso y apropiación de recursos marinos". 


\section{INTRODUCCIÓN}

Hoy más que nunca es urgente reconocer la inter-retroacción existente entre los procesos de descentralización, regionalización y democratización, al igual que es prioritario dejar de tratar estos procesos de manera aislada para proponer una visión en conjunto que otorgue respuesta a la complejidad territorial. Desde este punto de vista, la descentralización, por ejemplo, no quedaría reducida a sólo una redistribución del poder, sino que abarcaría todos los procesos cotidianos y de experiencias de la vida cotidiana. Con lo cual se intenta trascender tanto el reduccionismo, que no va más allá de las partes. como al holismo, que no ve más que el todo. Sí el cartesianismo tradicionalmente ha partido de los conocimientos y competencias disciplinarias, cuestión que ha causado una verdadera crisis del desarrollo, nuestra propuesta parte del reconocimiento (develamiento) esencial de las redes de coordinaciones. Es decir, se trabaja intentando hacer inteligible un conjunto de emergencias a partir de la relación entre discursos, hechos y poderes que tratan sobre los territorios locales y su desarrollo, avanzando hacia una potenciación de ellos en el sistema-mundo. De manera implícita, el análisis de estos procesos exige la aplicación de nuevos enfoques y métodos interdisciplinarios, junto a la existencia de modelizaciones que contengan un doble desafío: primero, estar abiertas a la reflexión, y, segundo, ser posibles de aplicar a la realidad local inmediata.

\section{ESPACIO Y TERRITORIO, EL TERRITORIO DEL TIEMPO EN EL ESPACIO}

Desde la óptica del tiempo, el espacio contiene múltiples actividades. Una Región, una Comuna, un sitio arqueológico, un conjunto de unidades habitacionales y una caverna, son manifestaciones de actividades que se han realizado en el tiempo, y cuya presencia denota esferas de acción y vínculos diversos. El territorio es espacio construido por y en el tiempo. De esta manera, cualquier espacio habitado por el hombre es producto del tiempo de la naturaleza, del tiempo de los humanos, de las distintas formas de organización, y de la concepción cosmogónica del tiempo. Es decir, en lo fundamental, el territorio viene a ser producto del conjunto de relaciones que a diario el hombre entretejió entre los suyos con la naturaleza y los demás.

Esta noción tiene la ventaja de incluir también una dimensión política del territorio. Es decir, en la relación con lo ambiental y con su alteridad el hombre se apropia de espacios, determina rutas, realiza señales y deja en la naturaleza su firma. Influye, afecta y controla acciones mediante el establecimiento de un dominio en un área geográfica específica. Se construye un sentido de la identidad espacial que guarda exclusividad y supone división en la interacción humana. La implicación de todo esto es un modo de comportamiento interior del contenedor que, en extensión (sincrónicamente, podríamos decir), desembocará, necesariamente, en conflicto por el espacio limitado y encuentro con otros, quienes también graban y dejan huellas en la apropiación sociocultural del espacio. El territorio es más que el espacio; son varios los territorios posibles en un espacio geográfico común. El comportamiento humano genera ritmos interiores que chocan unos con otros. En 
los territorios fluyen los acontecimientos internos significativos a cada colectividad. Como complemento no menor, el comportamiento humano genera también ritmos particulares. Intensidades. De manera que al hablar de territorio siempre estaremos hablando implícitamente también de dinámicas y conflictos. El pequeño pedazo de terruño conquistado sucede entonces por la metamorfosis que involucra a quienes viven (o han vivido ahí).

Junto a lo anterior, el territorio también complica a quienes nos dedicamos a investigarlo. Esto no es menor, supone incorporar al estudio del territorio el desarrollo de la Ciencia y del pensamiento, experimentándose una resemantización del espacio como campo relacional, multivariado y complejo, requiriéndose entonces nuevas metodologías para la producción de conocimientos acordes con el estatuto ontológico y metafísico del territorio, asumiéndose al territorio como una unidualidad espacio-temporal de la cotidianeidad siempre relacional, aplicada y conectiva que mantiene implícitamente presente a los entornos ambientales, de alteridad y de producción cultural y económica.

Figure 1 - Territorios vividos / Territorios normados ${ }^{2}$

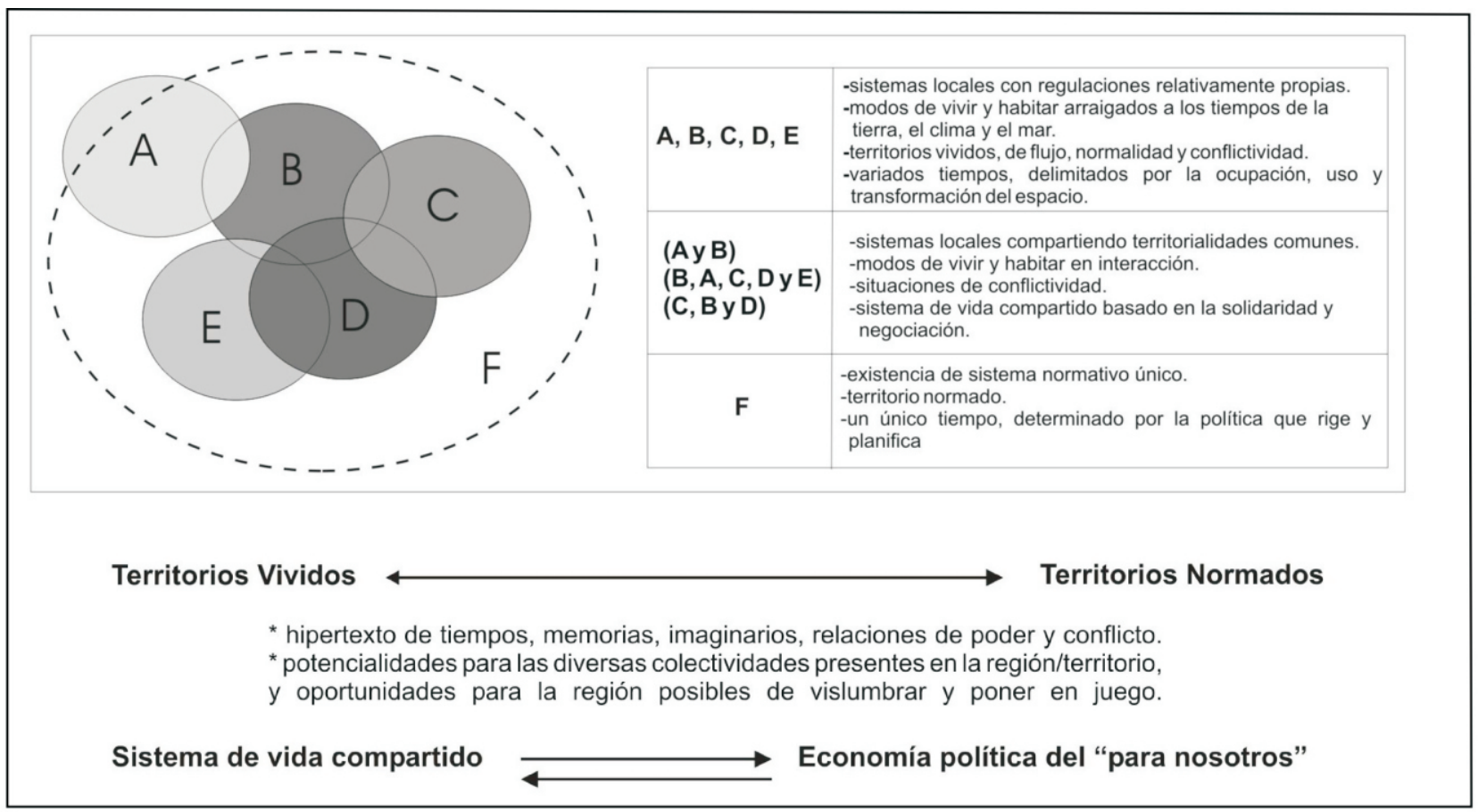

${ }^{2}$ Esta es una meta a la cual se ajusta el concepto semiótico de cultura, sistemas en interacción de signos interpretables (Geertz 1996: 27); signos de lo vivido, signos de lo normado. 


\section{NOCIONES: LOS TERRITORIOS Y SU INVESTIGACIÓN}

Los territorios se caracterizan por contar con socio y biodiversidades específicas, al punto que se les identifica por ellas. En la Región de Los Lagos en Chile, región-territorio en la cual hemos llevado a cabo básicamente nuestras tareas de investigación, existe una rica y generosa biodiversidad sobre la cual son evidentes los distintos modos de vida y hábitat. La constitución socioantropológica de este sector de Chile requiere estudios y análisis con aproximaciones teóricas y métodos interdisciplinarios que por sobre todo abarquen las dimensiones identitarias, ecológicas, económicas y políticas, y que, al mismo tiempo, resulten ser propuestas investigativas pertinentes; o sea, el análisis de la construcción territorial en esta zona, exige de un tratamiento imaginativo de la diversidad y su expresión territorial. Lo anterior, y dado los tiempos de globalización, se manifiesta aún más dada la tensión o clivaje existente entre tradición y modernidad, vivida en asentamientos humanos del borde costero en el sector sur de la Región, donde se pone en juego un armazón diverso de relaciones territoriales.

Complementando lo anterior, es evidente que las territorialidades en el sur de Chile, como en cualquier otro lado, se caracterizarán por el sentido identitario, la exclusividad y la división de la interacción humana. Es decir, las territorialidades se refieren a comportamientos desplegados en el territorio que se relacionan con la idea de cómo (con qué medios, elementos y motivaciones) se llega a habitary permanecer en un espacio sobre el cual se imponen los ritmos de vida y formas de interactuar con lo ambiental y con demás, más o menos distintos, más o menos similares.

De acuerdo con Tizon (1996) el territorio se asocia a las apropiaciones de grupos determinados, lo que en definitiva implica tanto inclusión como exclusión de unos sobre otros. En este sentido, la territorialidad humana estaría en el vértice de un gran número de acciones humanas que implican entre otros, poder, redistribuciones, funcionalidad, dependencia, albergue y conflicto. Otros autores (LECOQUIERRE y STECK citado por GIMÉNEZ, G., 2004) trabajando con los conceptos de territorio y territorialidad han señalado que éstas nociones remiten a una representación social del espacio que une al interior y separa del exterior a los habitantes de una localidad. Estos autores completan dicha noción atribuyendo al territorio una construcción colectiva, de grupo y ethos, referida a un "espacio apropiado" por un grupo social para garantizar su supervivencia y reproducción. De manera que el estudio del territorio, es decir, el espacio biofísico cargado de actividades humanas, de historia e imaginación, es material de interés político, económico y antropocultural. En la actualidad, a los estudios del territorio se les exige demostrar sistemáticamente las relaciones entre distintos elementos cercanos, pero también entre estos y otros elementos más lejanos. La exigencia incluye representar las distintas disposiciones de tipo contextural que unen y separan al mismo tiempo distintas escalas y niveles territoriales, así como también explicitar las potencias de los territorios a nivel intralocal, interterritorial, local/global.

En este sentido, la aproximación a los territorios se fundamenta en las concepciones y valoraciones que hacen de ellos, sus propios habitantes, pero también los territorios son el resultado de la construcción de conocimientos. Para el abordaje y conocimiento de los territorios, podemos decir junto con Claval (2002) que en cierta manera el espacio se asemeja a un texto, ya que está cargado de mensajes 
que, en ocasiones, le otorgan un sentido. Quienes lo crean, intentan plasmar en su realidad sus perspectivas, sus sueños y esperanzas.

Junto a estos últimos trabajos, lo de mayor importancia para hacer inteligibles las dinámicas y transformaciones territoriales es el concepto de modelización de Le Moigne (1999). El cual se considera parte de una epistemología constructivista para especificar una epistemología proyectiva constructivista caracterizada por incorporar fuertemente lo inesperado, procesual e irreversible y otorgar especial relevancia a la acción de un sistema tanto en su dimensión sincrónica como diacrónica. En este sentido, la modelización o representación de las acciones $\mathrm{u}$ operaciones (y no de los objetos o cosas) implica también considerar en el centro del análisis el tiempo creador (en el sentido bergsonniano). En nuestro caso, la acción es entendida como acción de distintas racionalidades que actúan sobre el territorio por medio de prácticas concretas. La modelización implicará entonces representar/diseñar intencionalmente símbolos sobre los usos y apropiaciones territoriales, en tanto las formas (sintaxis) que a la vez informan (semántica) y transforman (pragmática) los territorios; todo con el fin de comprender con pertinencia la trama de relaciones que construyen las prácticas y saberes en territorios específicos.

\section{PROBLEMATIZANDO: EL TERRITORIO Y LAS CIENCIAS DE LA COMPLEJIDAD}

El conocimiento tiende a una verdad, y para ello construye técnicas y metodologías. Buscándose construir convicciones, el conocimiento se obliga a prácticas y fórmulas políticas para acercarse por repetición y comprobación a un mundo único y conocido, cargado de concreciones medibles y situaciones reducidas a formas. El cartesianismo se ha fundado en "doctrina única por la ciencia positiva", respetando el análisis, o dicho de otra manera, la disociación de ideas, erigiendo así las barreras impenetrables entre las disciplinas (Le MOIGNE, 2001).

En la cotidianeidad de la ciencia, tanto el mundano como el científico, creen como verdaderos e intransables la información proveniente del trabajo científico ¿Qué pasaría si un estudio científico revela que son falsas algunas de las creencias que hoy sostenemos? Los científicos sociales estamos presionados a neutralizar la efectividad de nuestros estudios: el sociólogo limita su estudio a temas "seguros" (por ejemplo, la estructura social, aplicando para ello métodos impersonales como encuestas y estadísticas). Por su parte el antropólogo, ha transformado en un credo profesional el estudio de otras culturas (llámense culturas indias, primitivas, pobres, etc.) con el fin de lograr un análisis de nuestra propia cultura.

Hoy en día, tenemos quizás más que nunca una necesidad de situar, reflexionar y cuestionar nuestro conocimiento, es decir, "conocer las condiciones, posibilidades y limites de sus aptitudes para alcanzar la verdad que busca" (MORIN, 1994, p.18). Como señala Ribeiro (1976), es necesario, pero en gran medida también improcedente, ir más allá de las certidumbres, atravesar los miedos y avanzar en la comprensión de los procesos. El miedo de lo que podamos descubrir nos impulsa a rechazar un examen cuidadoso de nuestras creencias más profundas, pero tal examen es ineludible si queremos llegar a comprender el mundo en nuestros días.

Introducirse en el conocimiento que supere las certezas, disyunciones y reducciones deterministas, implica investigar apuntando hacia los sentidos relacionales de "la realidad". 
Considerando que la raíz cognitiva muestra que el pensamiento científico es un pensamiento que relaciona, que funciona por metáfora (Le MOIGNE, 2001) se tendrá como consecuencia la posibilidad de abrir la investigación hacia campos de interpretación y comprensión de los fenómenos y sus fronteras. En el caso de las actividades humanas, todas ellas, poseen niveles de correspondencia que fractalizan las realidades en unidades de espacio y tiempo con intersticios permeables hacia procesos abiertos, continuos y discretos. En el intersticio, puntos que simultáneamente pertenecen al espacio interior y al espacio exterior, y donde se produce el intercambio de información y energía, el dinamismo, la imaginación y el juego fluyen para hablar de la vida, de la integralidad, y del pasar de lo homogéneo/heterogéneo. Ubicarnos ahí, en la frontera permeable movible y penetrable, nos identifica nuevamente con asociaciones de ideas, creencias y conceptos que dialogan, a fin de constituir miradas nuevas, perspectivas oxigenadas, acerca del territorio.

Curiosamente el avance de la Ciencia nos ha demostrado que ni el holismo, ni el relativismo son posibles. Tanto el principio de indeterminación como el principio de incompletitud obligan a conocimientos con base a abrirse hacia la desorganización y reorganización. La no determinación, que no es simple indeterminación o ignorancia, es creación, surgimiento de otras determinaciones ya existentes o por surgir, emergencias sin que nada las predetermine, salvo las mismas interacciones. Al existir creación y recreación continua reaparece la paradoja del tiempo. En Las leyes del caos Prigogine (1997) comenta las llamadas estructuras disipativas o estructuras de no equilibrio, las cuales nos permiten comprender todo sistema como una relación de relaciones y no como una simple estructura inmóvil. La relación de relaciones conjuga continuamente tanto la energía que produce y gasta como la interacción con el mundo externo: ambos nos hablan de lo imprevisible. En consecuencia, lo inconcluso toma sentido de realidad buscando colocar con fuerza sobre la mesa las coexistencias de acontecimientos y cambios. Habitamos un "universo donde cada instante es portador de novedad, es decir, de un tiempo y de fenómenos irreversibles. Este universo no es determinista sino 'probabilista', y hasta 'posibilista', y esta condición es 'más cercana, en definitiva, a nuestra condición humana'" (SPIRE, 2000, p.43).

De manera que conocer las condiciones, posibilidades y límites del conocimiento implica tender los esfuerzos hacia verdades procesuales. Las Ciencias Sociales abocadas a los estudios territoriales no escapan a esto y se resignifican por medio de enfoques, metodologías e intereses temáticos que en conjunto transgreden lo tradicional y otorgan una esencial preocupación al hombre, sus construcciones y cambios. Se elucida entonces un espiral de conocimientos, saberes y experiencias vinculadas a la producción, negociación y tráfico de significados y significaciones socioculturales posibles de reconocer situándose en espacios geográficos más o menos definidos. ${ }^{3}$

Desde aquella Ciencia de los límites, reconocedora de sus límites tradicionales y al mismo tiempo transgresora de los mismos, se ha avanzado en espiral hacia la emergencia del tiempo en tanto en la categoría de la transformación y cambio: el tiempo se transforma en la moneda de cambio para el deseo de vida, de lo aún no

\footnotetext{
${ }^{3}$ Este espiral de conocimientos, saberes y experiencias se condice con la doble hélice de ADN propuesta por Watson y Crick en 1953 en su artículo "A Structure for Deoxyribose Nucleic Acid" publicado en la revista Nature, v.171, n. 4356, p. 737-738 (25 de abril de 1953). “Desde entonces la doble hélice se ha convertido en el icono de la ciencia moderna: la Mona Lisa de la ciencia moderna" (KEMP citado por LACADENA, 2003).
} 
pensado y del sentido de las existencias. El transcurrir en espiral de las realidades del hombre nos ha llevado, sin necesariamente enunciarlo, a vivir con fuerza en los tiempos contemporáneos.

Estas Ciencias nacen comprometidas con la conectividad creadora. Multiplicidad, vínculos, transformaciones, emergencias, son algunas de la "buenas nuevas" que trae la complejidad. Las múltiples conexiones señalan los múltiples vínculos que sugieren también variadas conexiones. Conectarse es la apertura para el pensamiento. La complejidad apuesta a un acercamiento a lo múltiple, una especie de mapa vivo otorgado a mentes e identidades que no están cristalizadas todavía y que poseen la voluntad de embarcarse en esa travesía que no soporta mapas con coordenadas fijas (RAJCHMAN, 2004, p.10), porque pensar es sentir. Desde las Ciencias de la Complejidad, entonces, se piensan/ reconocen/construyen territorios del conocimiento que no están del todo determinadas. Verdaderamente se trata de un desafío que se nos brinda para enunciar procesos situados y vinculados territorialmente. Territorialización de vínculos, territorialización de tiempos. “... Relacionar bien, ¿no es esto el pensamiento complejo?" (LE MOIGNE, 2001, p.13).

\section{CONSTRUCCIÓN 1: ANTROPOLOGÍA DEL TERRITORIO, “CAPTURANDO" EL TERRITORIO}

La territorialización significa vínculos de variadas conexiones y, como tal, es un proceso que debe suceder. El territorio es tiempo. Varios tiempos depositados. Entremezclados. Vividos. Coordinación de relaciones. La trasgresión de los límites del conocimiento y los tiempos vividos confluyen en una Ciencia dedicada al territorio. Se trata de una Antropología del territorio, la cual devela al espacio (en tanto soporte biofísico de las actividades humanas), no como una entidad perteneciente al orden de la yuxtaposición, sino más bien como una forma, proceso, de estratos imbricados. O sea, la Antropología del Territorio resemantiza el espacio, proyectándolo a dimensiones temporales entretejidas. Con esta antropología, el territorio no sólo tiene sentido, sino que también adquiere significados y significa. La Antropología del Territorio se presenta en consecuencia como un pensamiento situado y abierto. Pensamiento situado para conocer la profundidad del tiempo de las memorias territoriales; pensamiento abierto a los imaginarios del tiempo de las transformaciones del territorio.

Enun sentido operatorio, la investigación del territorio es una "captura", en tanto aprehensión (lat. apprehensio), desplegada desde los territorios del saber y conocer, para aplicarse sobre los territorios de las experiencias situadas con intensidad y extensión. La Antropología del Territorio implica entonces reconocer el cruce del tiempo con el espacio a partir de memorias e imaginarios territoriales; desde aquí se abren posibilidades investigativas para tratar abiertamente el juego simultáneo de distintas formas y modos de vivir y habitar, posibles estas mismas de convertirse en atractores investigativos. Decidir qué tipo de relaciones queremos establecer con el territorio estudiado, cómo y qué tipo de registros son posibles realizar, y para qué se realizan estos, serían algunas de las cuestiones básicas a resolver durante la aprehensión territorial. 
Figura 2 - Capturando el territorio

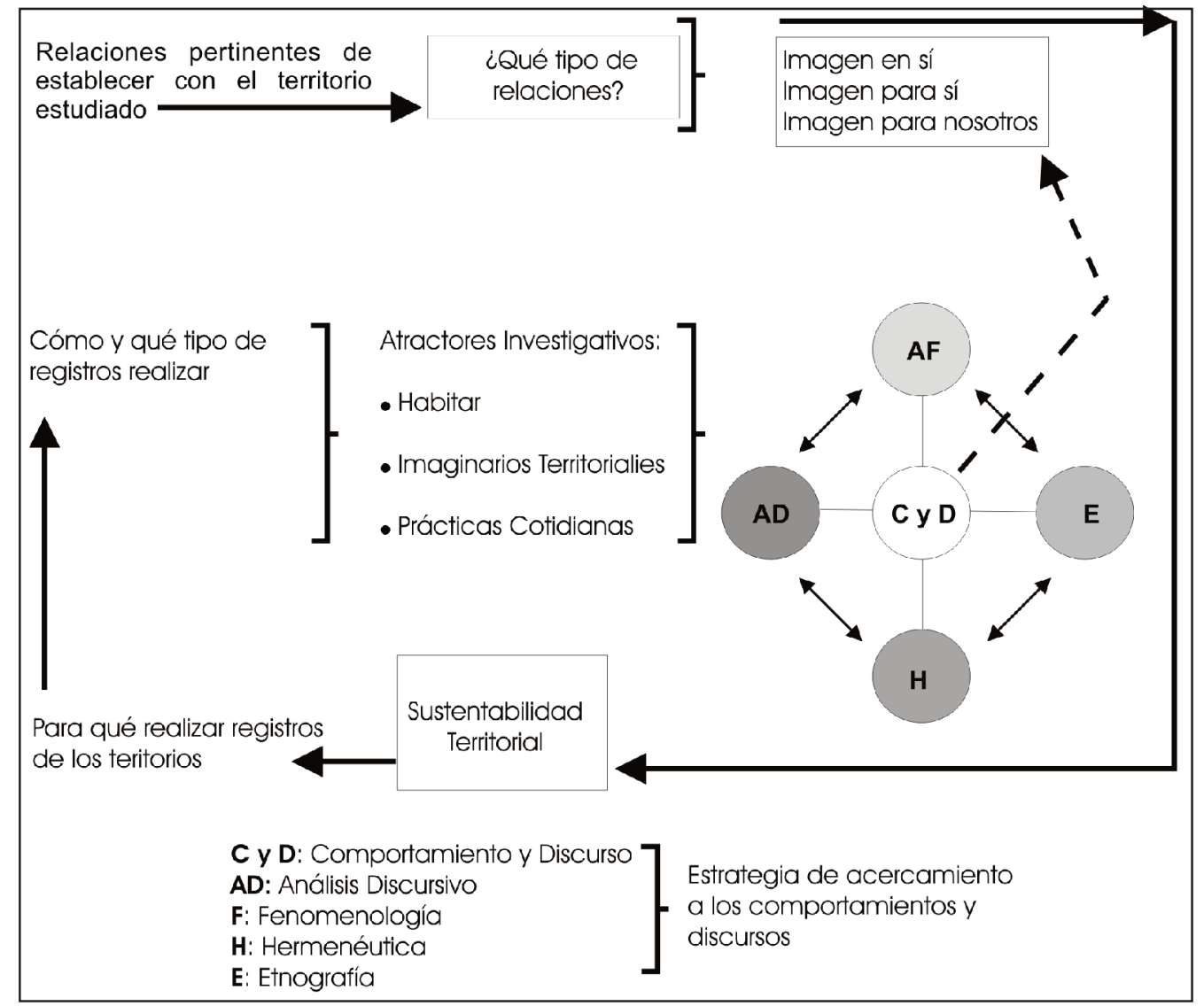

Esta representación de acciones intenta modelizar la "captura" de las experiencias situadas en el territorio. Es innegable la cercanía de este procedimiento con la etnometodología (COULON, 1995) y el interaccionismo simbólico (BLUMER, 1982). En todos estos procedimientos los discursos también son prácticas, y como tales requieren de la observación directa (incluso con rasgos participativos) así como también del estudio de la oralidad. La diferencia de la Ciencia enunciada, y el tipo de captura del territorio que ella potencia, radica en que esta no abandona la dimensión ética del pensar y abre los territorios hacia su sustentabilidad. La sustentabilidad del territorio, en este caso, remite a una forma no lineal del tiempo para finalmente volver a reconocer a los habitantes de un lugar insertados en el armazón que se produce. Como tal, la captura del territorio construye una réplica en proceso del territorio, abierta y en transformación. A partir de ciertos esquemas generativos que permiten a los habitantes de un lugar percibir, ordenar y actuar en el mundo, se logra ir capturando parte de las territorialidades y reconstruir los territorios. Estos esquemas generativos se conforman a lo largo de la historia, suponiendo la interiorización de normas, pautas y modos de actuar en el tiempo y en el espacio; a partir de ellos, se producen los pensamientos, percepciones y acciones en el mundo. Investigativamente, los esquemas generativos territorializados son posibles de captar/de construir mediante una estrategia que organiza/construye una "caja de herramientas" con varias entradas heurísticas, que nos permite, de manera 
más o menos concreta, aprehender / conocer/capturar tanto las formas en que se organizan distintos modos de vivir y habitar en el territorio, ${ }^{4}$ como los imaginarios territoriales. Ambos atractores investigativos plasman analíticamente el hacer/decir social. ${ }^{5}$ De manera que la conducta humana, o la cultura, es vista como acción simbólica, a la que se le pregunta por su sentido y valor de manera rigurosa (GEERTZ, 1996); ya que es en el fluir del comportamiento y el discurso donde estos esquemas encuentran su articulación para construir a formas culturales territorializables. En este sentido, con el hábitat, más allá de manifestar la defensa y control sobre el ambiente y los territorios, uno de los mayores intentos que pretende realizar la Antropología del Territorio es avanzar en función de la construcción de categorías de fuerte identificación de los grupos con su hábitat. Por su parte, con los imaginarios territoriales, en tanto matrices ideoafectivas (CARRETERO PASÍN, 2004), se pretende reproducir la creatividad de los grupos y su forma de ver el mundo para actuar en él, en ocasiones para transformarlo, en otras para preservarlo. De manera que

\footnotetext{
${ }^{4}$ Las formas de organización de distintos modos de vivir y habitar en el territorio lo señalaremos simplemente como "el habitar".

${ }^{5}$ La hipótesis que subyace a esta estrategia metodológica es que las sociedades contienen en sí mismas sus propias interpretaciones. Lo que se necesita es aprender la manera de tener acceso a ellas (GEERTZ, 1996, p.372). Tanto los imaginarios territoriales como el habitar pueden ser tratados como formas culturales particulares de los esquemas generativos mencionados. $\mathrm{Y}$ aunque Levi-Strauss señaló que las formas culturales pueden ser tratadas como un texto de códigos necesarias de descifrar (pues la estructura es la misma, general, universal), la Antropología del Territorio retoma la postura de Geertz en cuanto a que las formas culturales deben ser más bien interpretadas, particularmente. Al señalar Levi-Strauss la posibilidad de generalizar el estudio cultural explicitó también características universales del hombre: tabú del incesto, producciones mentales similares a toda la especie (mitos); Geertz, por su parte, menciona que aún adoptando una determinada línea teórica, el investigador no puede escribir una teoría general de la interpretación cultural pues el estudio etnográfico es de carácter específico dada la naturaleza de su objeto de estudio (inscripción). De esta manera, la Antropología del Territorio abarca la comprensión/aprehensión del habitar y de los imaginarios, todo en función a cómo se articula el hacer/ decir social en situaciones concretas que organizan percepciones, significaciones, emociones, conceptos, actitudes.
}

el hacer/decir social se aprehende por medio de la observación, el registro y la interpretación de los comportamientos desplegados sobre los espacios y las experiencias acumuladas a través del tiempo, posibles también de registrar, analizar e interpretar mediante lo dicho (discurso). En definitiva, la Antropología del Territorio sitúa a los sujetos por medio de sus hábitats e imaginarios territoriales para, desde ahí, develar posibilidades de sustentabilidad de sus territorios, es decir, con una Antropología del Territorio se amplía "el universo del discurso humano" (GEERTZ, 1996, p.27), y se coayuda para que el sujeto territorial se abra al mundo desde sus propios sentidos existenciales.

\section{CONSTRUCCIÓN 2: TERRITORIOS VIVIDOS / TERRITORIOS NORMADOS EN LA REGIÓN-TERRITORIO}

\section{Lo anormal, lógicamente secundario, es existencialmente primario Canguilhem}

La imagen de los territorios construida a través de la Antropología del Territorio deviene en hipertexto de tiempos, memorias, imaginarios territoriales, relaciones de poder y conflicto. Esta intensidad acumulada remite así a memorias, tradiciones, usos y costumbres, pero también remite e incluye a lo nuevo, a lo emergente. Por otro lado, los territorios descubiertos por medio de la Antropología del Territorio se expresan también en extensión, abarcando espacialidades comunes, de tal suerte que se hacen inteligibles encuentros / desencuentros en territorialidades comunes con usos y costumbres variadas. Todo esto queda expresado por ejemplo en la Isla de Chiloé, territorio litoral en el cual no 
es posible signar taxativamente a los campesinos con delimitadas actividades. En Chiloé, específicamente en el sector de Cucao, los campesinos se dedican tanto a actividades a la orilla del mar como en el bosque y el campo; conocedores de las bondades de la tierra y el mar organizan sus trabajo en función a un verdadero reloj de la tierra y el clima. Como caleta de mar abierto, orientada hacia el Océano Pacífico, Cucao presenta un escaso desarrollo de la tecnología extractiva junto a una fuerte presencia de comunidades Huilliche. Se trata de un asentamiento de 90 viviendas (INE, 2005) y 229 habitantes (111 hombres y 118 mujeres) (INE, 2002). En cuanto a la economía local las actividades predominantes son la pesca, extracción de leña, pequeña agricultura y el turismo en verano. De la pesca se extrae machas (Mesodesma donacium), cochayuyo (Durvillaea antartica), lapa (Fissurella spp.), piure (Pyura chilensis), róbalo (Eleginops maclovinus) y corvina (Cilus giberti). En Cucao se muestran entramados territoriales importantes: los tiempos de las memorias y tradiciones potencian distintos vínculos con lo ambiental.

Una segunda expresión de los territorios posibles de cartografiar en la región/ territorio denominada como Región de Los Lagos, corresponde a la relación que mantienen las familias de pescadores artesanales con el mar en los distintos asentamientos de pescadores que se ubican en esta región-territorio. En la Caleta Pichicolo, Comuna de Hualaihué, las familias de pescadores artesanales habitualmente se dedican a muchas de las actividades también realizadas por los campesinos chilotes. Por varias décadas han existido continuas migraciones desde Chiloé hacia otros puntos del país y el extranjero; Pichicolo ha sido una de las tantas caletas que han recibido migraciones familiares desde Chiloé. De manera que parte de los usos y costumbres chilotas también han migrado hacia este sector, resemantizándose en algunas partes y cambiando también en otras partes. La caleta Puntilla Pichicolo se encuentra ubicada en el Estero Pichicolo en el sector norte de la comuna de Hualaihué, en el mar interior de Chiloé, se trata de una pequeña caleta de pescadores con sólo 158 habitantes (INE, 2002). En cuanto a la economía local, la población se dedica principalmente a los labores asociados con el mar, la mayoría desarrolla actividades tales como pesca demersal, recolección de mariscos, buceo, acuicultura y salmonicultura, siendo la pesca demersal la actividad más rentable por medio de la extracción de la merluza del sur (Merluccius australis) que se extrae durante todo el año, excepto el mes de agosto por veda biológica. La mitilicultura con líneas de captación de Choritos (Mythilus chilensis) es una actividad altamente rentable. Un factor positivo son las condiciones geográficas favorables para la captación de semillas de mitílidos. Los tiempos en Pichicolo son los tiempos que sus habitantes van poniendo en uso y práctica, aprendidos hasta cierto punto en el archipiélago de Chiloé y asimismo resignificados e innovados en el nuevo sector y los reclamos y oportunidades que el ambiente y la vida cotidiana otorgan. Simultáneamente, los territorios vividos aquí se encuentran con el tiempo único de las normativas. Si hasta 15 años atrás las familias de pescadores se dedicaban principalmente a la pesca de merluza, ahora las disposiciones legales y el sistema de cuota de captura los empujan a modificar la tradicional relación que han mantenido con el mar. Ya el mar no puede seguir siendo una fuente inagotable de recursos: surgen posibilidades de cultivar el mar y con ello varias alteraciones a nivel práctico, social y cognitivo, junto a algunas emergentes estrategias de 
ocupación. La nueva imagen del territorio por tanto resulta ser una intersección entre los territorios vividos y normados, vislumbrándose una conflictividad entre los tiempos de la cotidianeidad y el tiempo único de la normatividad; su aparente resolución es igualmente una expresión de lo que son los territorios. Desde la óptica de la norma, la cotidianeidad de los territorios vividos se transforma en anormalidad necesaria de corregir.

Complementando lo anterior, en la Región de Los Lagos existe una tercera expresión de territorialidad donde se ponen en juego distintas posibilidades. Lo que sucede en las relaciones cotidianas actuales entre grupos de distinto origen cultural y con presencia histórica en esta parte de Chile, se han plasmado en el presente en una normativa de planificación que postula arbitrariamente una vocación pluricultural para esta región-territorio. ${ }^{6}$

Figura 3 - Contracción/expansión del territorio

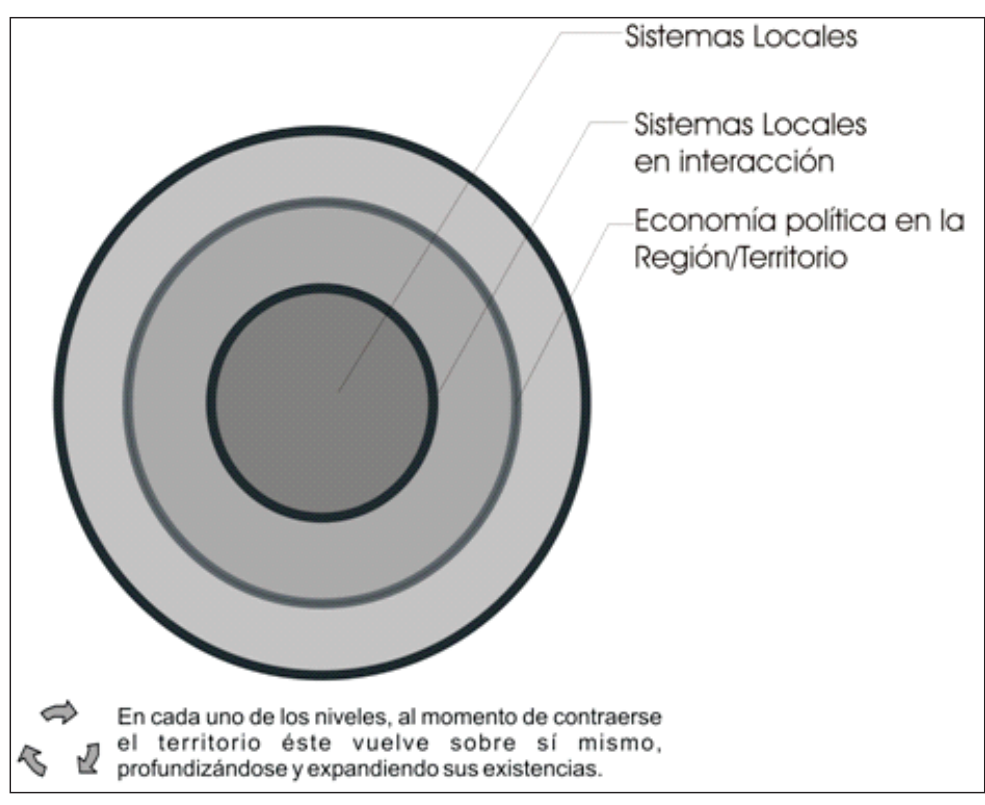

${ }^{6}$ La vocación pluricultural queda definida en la Estrategia de Desarrollo Regional de la Región de Los Lagos (2000 - 2010). La norma expresa valores de una parte de la sociedad. Luego, no será posible que surjan las normas, sino es por la decisión de un sujeto que "declara una intención normativa y toma una decisión normadora o normalizante" (Curso no publicado y dictado por Canguilhem en 1942-43 en la Facultad de Letras de Estraburgo, citado por Le BLANC, 2004, p. 20).
Entre los grupos presentes se destacan las comunidades mapuche, antiguos habitantes de gran parte de la zona centro sur de nuestro país, y que territorialmente son conocidos en la Región de los Lagos como huilliche.

Íntimamente, en lo más cercano a su morada, los huilliche han ido construyendo varias territorialidades según las particularidades ambientales del Futahuillimapu (gran territorio huilliche), las potencialidades de estas geografías, las tradiciones y las regulaciones poliformes y verticales que por largos años les han aplicado el Estado-Nación y los empresarios. En la actualidad, algunos huilliche se mantienen más cercanos a la interculturalidad, otros incluso reacios a la incorporación, algunos más proclives a coordinar fuerzas y estrategias con los huincas (blancos). Al contrario de lo que se ha señalado tradicionalmente por las Ciencias Sociales, la norma aquí ha sido desplegada a posteriori; parafraseando a Canguilhem, diremos entonces que sólo una vez que el acontecimiento se extiende/sucede, y resulta social y valorativamente insuficiente para un sector, surge la norma (LE BLANC, 2004). De manera que la pluriculturalidad y el tiempo oficial único que promueve la norma van incitado un hipertexto de espesor distinto en el cual se congregan tanto potencialidades para las comunidades huilliche como oportunidades para la región/territorio. Pero también, quiebres y debilidades que amenazan con un, no siempre deseado, equilibrio desequilibrado. En este sistema de vida se ponen en juego distintas manifestaciones de interacción no exentas de conflicto. Pero también, y como siempre, emergen verdaderas adaptaciones a causa de la misma instauración de nuevas normas. Quedamos en presencia de la 
configuración de una economía política en esta región-territorio; o sea, la arbitrariedad política, productora de normatividad y con ausencia de vínculos con la vida sociocultural, siempre que afecta a los territorios vividos, se superpone con ellos y genera nuevas formas de individuación en los territorios. Siendo la normalización un intento de racionalización de la regiónterritorio, aparece como regulación y disciplinamiento. Puesto esto en una perspectiva diacrónica, señala al territorio como la confrontación entre principios estructurantes (normas) y la historia de su problematización.

\section{CONSTRUCCIÓN 3: SENTIDO PATRIMONIAL}

A partir delas construcciones enunciadas anteriormente se demuestra un accionar interdisciplinario que da cuenta del funcionamiento de las temporalidades en los espacios apropiados por medio de la cotidianeidad, relacionándose el desarrollo local a condiciones medioambientales e históricas del lugar, así como a las condiciones y diferentes cursos (hechos, acontecimientos) que han posibilitado $y$ posibilitan diferentes sistemas y modos de vida, y de producción cultural y económica. La viabilidad de obtener sustentablemente productividad a partir de patrimonios naturales y culturales requiere un profundo cambio a nivel de las mentalidades e imaginarios de quienes investigan los territorios de comunidades tradicionales, esto involucra (ver el Esquema "Sentido Patrimonial") al menos revertir el slogan promovido por el discurso del desarrollo sostenible "pensar globalmente y actuar localmente" que no hace más que darle fuerza al discurso de la globalización.

El reto es "pensar las singularidades locales y construir una racionalidad capaz de integrar sus diferencias, asumiendo su inconmensurabilidad, su relatividad y su incertidumbre" (LEFF, 2003, p. 33); se trata del saber ambiental que implica un modo de vida sustentable en lo local, que sin desconocer la marcha de los procesos de globalización, avanza hacia una propuesta que proviene de un proyecto social fundado en la cultura, la democracia y la productividad de la naturaleza: quienes mejor conocen y pueden llegar a cuidar los patrimonios son quienes viven en el lugar, en ellos se congregan los tiempos para crear territorios y expandirse en territorialidades.

También se espera que la sustentabilidad productiva se instale como modo de vida. Por las características que poseen las Universidades Regionales, deberían ser éstas - junto a ciertas agrupaciones de la sociedad civil, tipo ONG's- las principales impulsoras y gestoras de una conciencia social y política que busque transformar las actuales estrategias de poder presentes en el saber. La Universidad Regional al recurrir a un accionar cercano a los enfoques socioanalíticos puede impulsar un importante avance, potenciándose una conciencia desde las bases que posibiliten la ejecución y puesta en escena de actividades económico-sustentables con sentido patrimonial, ${ }^{7}$ como son el turismo a escala relacionado con la visita a reservas y santuarios de la naturaleza, la arquitectura y construcción en madera de Chiloé, la pesca y agricultura basada en sistemas tradicionales de cultivos y modos de vida comunitario, junto al uso y manejo sustentable de la biodiversidad (y ya no de simples recursos biológicos

\footnotetext{
${ }^{7}$ Sobre enfoques socioanalíticos o análisis institucionales ver, por ejemplo, René Lourau et al, 1979, Análisis institucional y socioanálisis, editorial Nueva Imagen, México; Jesús Ibáñez, 1991, El regreso del sujeto. La investigación social de segundo orden. Edit. Amerinda, Chile; Jesús Ibáñez, 1985, Del algoritmo al sujeto. Perspectivas de la investigación social, Siglo XXI, España.
} 
tangibles), la acuicultura con verdadera responsabilidad social, etc..

Los puntos señalados, sin embargo, resultan ser una condición necesaria pero no suficiente para la sustentabilidad territorial. Es preciso un tercer proceso: se esperaría que desde lo social se promueva la creación de una nueva politica del lugar y de la diferencia. La cultura construida y transformada permanentemente a partir del sentido del tiempo que muestra las luchas por la identidad, por la autonomía y por el territorio, reclama por una política del ser, "una política del devenir y la transformación, que valora el significado de la utopía como el derecho de cada individuo y cada comunidad para forjar su propio futuro". La política del ser es "resistencia a la hegemonía homogeneizante de la globalización económica y afirmación de la diversidad creativa de la vida, construida desde la heterogénesis cultural-ecológica" (LEFF, 2003, p. 33-34).

Figura 4 - Esquema 'Sentido Patrimonial'

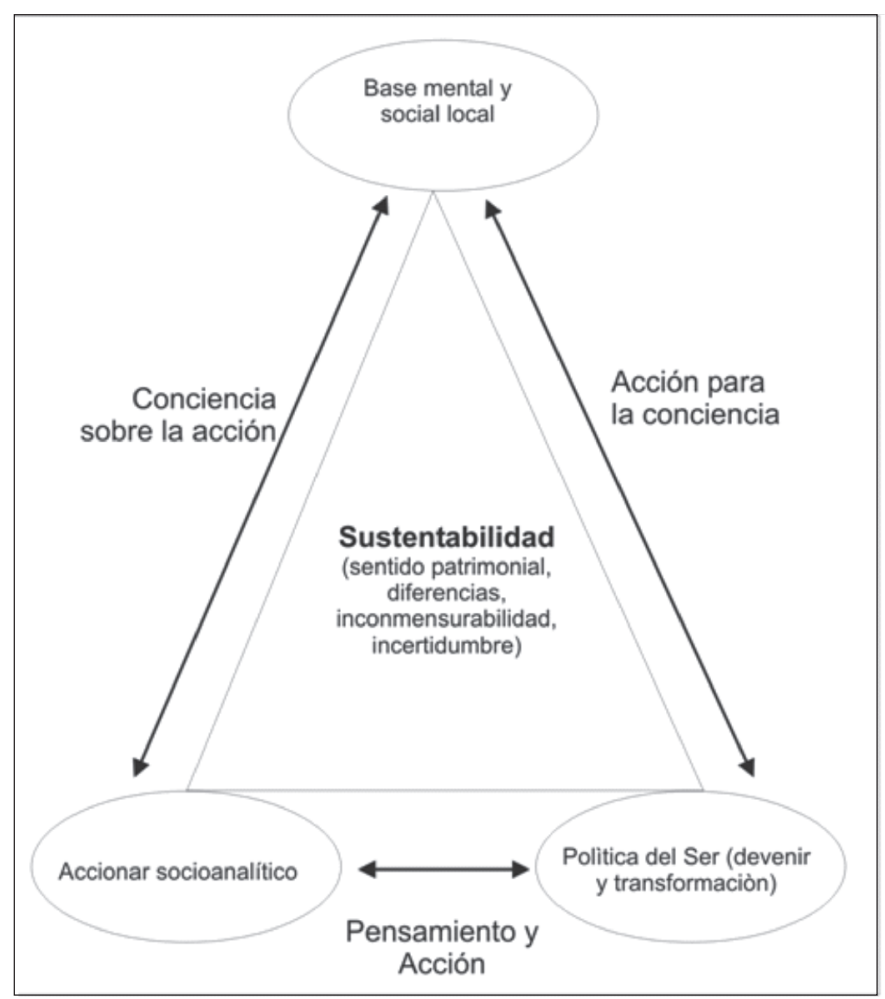

Iniciar un proceso de búsqueda y creación de sentido patrimonial significaría así tener la sustentabilidad como un compromiso y ética de vida, e incluso también como precondición de la competitividad e internacionalización. La búsqueda y creación de sentido patrimonial estimularía cambios a nivel social; su base, no así su consecuencia, sería lograr una economía sustentable amparada por una política de transformación o política del lugar, donde no sólo se separe la cultura y el Estado sino, y por sobre todo, se encuentren comunicativamente. Para Ricoeur la base del sentido se encuentra precisamente en regresar al mundo de la acción. Es aquí donde se encuentra todo el sentido patrimonial. Visto así, cualquier estudio, política o programa de sustentabilidad y conservación de los territorios locales donde habitan y viven comunidades tradicionales, conviene basarlo en una forma de pensar y actuar no lineal, ni determinista. Una acumulación de saber sobre el funcionamiento del medioambiente y la cultura permite avanzar en el diseño de propuestas alternativas en torno a lo socioambiental y tomar decisiones que no responden a contingencias político-económicas, sino a criterios que discutan temporalidades de larga duración originados por preocupaciones en el seno de las comunidades tradicionales, todo lo que iría en función a crear condiciones de bienestar para la población, siendo el genuino resultado de una cierta productividad de bienes y servicios sostenida en el tiempo y diversificada en un doble proceso permanente de complejidad y simplificación. En este suceso existe un movimiento como resultado de la concurrencia de campos de fuerza en diverso sentido: mientras la base social local empuja-presiona, para que se logren sus deseos y aspiraciones que emergen desde su memoria colectiva; el accionar 
socioanalítico por su parte motiva y ensaya la reflexividad sobre la base social local, recibiendo de ésta una retroacción en forma de conciencia de la acción. La base social local, al mismo tiempo presiona al devenir para construir una acción política del ser, emergiendo un atractor que reúne a la conciencia, la acción y el pensamiento en el tiempo.

\section{EXODUCCIÓN: CONSTRUCCIONES EN LAS QUE NOS HACEMOS PAULATINAMENTE SEMEJANTE A LA COSA CONOCIDA}

Las dos construcciones planteadas (1. Captura del Territorio; 2. Territorios vividos / territorios normados) muestran al territorio como acontecimiento y transformación. Las relaciones que suceden en el territorio, así como los efectos y retroacciones de estas mismas relaciones, construyen los territorios en armonía/desarmonía. Cuanto sucede en el territorio es trazado, tanto libre, como controladamente. Mientras que lo primero remite a múltiples experiencias de apropiaciones que se dan en el tiempo y cuyo transcurso orienta variadas formas de vivir y habitar, y cuyas regulaciones se basan principalmente en las costumbres; el control por su parte, básicamente de tipo político, busca producir encuadres convenientes, eliminando la multiplicidad a través de una única mirada.

La cotidianeidad del territorio, como acontecimiento, proviene de territorios vividos, múltiples y locales. Cada uno delos territorios con sus propias temporalidades. Son justamente los sistemas locales, situados y al mismo tiempo mucho más amplios que un espacio físico, los que son vividos por los sujetos y actores que lo han construido.
A partir de lo anterior, es importante subrayar que tan significativa como la relación local/global, muy estudiada por economistas y geógrafos, es la relación posible de mostrar entre territorios locales, y entre éstos, la globalidad. En este sentido, el desarrollo de los territorios es más bien un proceso del tipo local/global/ local que termina desorganizándose y reorganizándose continuamente. Tener como meta el estudio de los territorios considerando esta orientación implica, por lo tanto, ajustar tanto el corpus discursivo como la estrategia metodológica a un verdadero tratamiento hermenéutico del territorio, cuya operatoria, en última instancia, elucida interacciones entre sistemas locales de signos de lo "vivido" y "normado" (Figura 1). Según Geertz se trata de "sistemas en interacción de signos interpretables" (GEERTZ, 1996, p.27). La sensibilidad investigativa que construye la Antropología del Territorio, equivale a fin de cuentas, y tal como lo señala Giannini apud Figueroa (2004, p.95) a "hacerse paulatinamente semejante a la cosa conocida", equivale a contar con una "caja de herramientas" pertinentes para el objeto de estudio. Sensibilidad y comprensión del objeto de estudio en la que el propio investigador se reconoce recorriendo realidades materiales, culturales y simbólicas. En la relación entre territorios vividos/territorios normados, se denota la complejidad territorial (THER, 2006): los territorios normados remiten inevitablemente a la idea de territorios vividos. Se trata de una normalización entremezclada con la normalidad, y de una cotidianeidad que, entremezclada con el control y la norma, ha interiorizado lo demás. Esto hace que la región-territorio cambie. Vida sociocultural y norma política establecen el funcionamiento de la regiónterritorio por medio de interacciones de tipo solidario y conflictivo entre distintos 
imaginarios y habitantes, al tiempo que permiten aclarar cuestionamientos sobre las formas de acercarse, aprender y tratar a los territorios. Lo vivido y lo normado, son el corazón del territorio a estudiar, y la base para estimular el sentido patrimonial como una real modalidad cognitiva para la sustentabilidad de los territorios locales.

\section{REFERENCIAS}

BLUMER, H. La posición metodológica del interaccionismo simbólico. In: El interaccionismo simbólico: perspectiva y método. Barcelona: HORA, 1982. p. 44-53.

CARRETERO PASÍN, A.E. La relevancia sociológica de lo imaginario en la cultura actual. Nómadas Revista Crítica de Ciencias Sociales. Universidad Complutense de Madrid, n. 9, Ene.Junio. 2004. Disponible en: http://www.ucm.es/ info/nomadas/9/ecarretero.htm

COULON, A. La revolución etnometodológica. In: Etnometodología y educación. Barcelona: Paidós, 1995, p. 13-30.

CLAVAL, P. El enfoque cultural y las concepciones geográficas del espacio. Boletín de la AGE, n. 34, 2002, p. 21-39.

FIGUEROA, Maximiliano. Entrevista a Humberto Giannini. Una Ciudad para el paso humano. Revista Electrónica Mensual de la Universidad Alberto Hurtado. Sept.- Oct.-Nov. 2004. Disponible en: http:/ / www.boletin.uahurtado.cl/2004/1004/ entrevista_giannini.pdf

GEERTZ, C. La interpretación de las culturas. Barcelona: Gedisa Editorial, 1996.

GIMÉNEZ, G. Territorio, paisaje y apego socioterritorial. In: Primer Foro. Regiones culturales Culturas regionales. Ciudad de México: Conaculta, Dirección de Vinculación Regional, 2004.

INSTITUTO NACIONAL DE ESTADÍSTICAS INE. XVII Censo Nacional de Población y VI de Vivienda, 2002.
LEFF, Enrique. La Geopolítica de la Biodiversidad y el Desarrollo Sustentable: economización del mundo, racionalidad ambiental y reapropiación social de la naturaleza. Revista LIDER, Número Especial, Año 8, n. 11, Primer Semestre 2003. CEDER / ULA, Osorno, Chile.

LE BLANC, Guillermo. Canguillem y las normas. Buenos Aires: Ediciones Nueva Visión, 2004.

LE MOIGNE, Jean-Louis. La asociación de ideas, fundamento del pensamiento complejo. Artículo publicado en francés por Transversales (Febrero 2001), y en castellano en Iniciativa Socialista (Verano 2001). Disponible en: http:/ / www.inisoc. org/61moigne.htm

LE MOIGNE, Jean-Louis. La modélisation des systemes complexes. París: Dunod, 1999.

MORIN, Edgar. El Método Tomo III. El conocimiento del conocimiento. Madrid: Cátedra - Teorema, 1994.

PRIGOGINE, Ilya. Las leyes del caos. Barcelona: Ed. Crítica, 1997.

RAJCHMAN, John. Deleuze, un mapa. Buenos Aires: Ediciones Nueva Visión, 2004.

RIBEIRO, Darcy. El proceso civilizatorio (de la revolución agrícola a la termonuclear). México D.F.: Editorial Extemporáneos, 1976.

SPIRE, Arnaud. El Pensamiento de Prigogine. Santiago de Chile: Editorial Andrés Bello, 2000.

THER RÍOS, Francisco. Complejidad territorial y sustentabilidad: notas para una epistemología de los estudios territoriales. Revista Horizontes Antropológicos, año 12, n. 25, 2006, p.105-115.

TIZON, Philippe. $\mathrm{Qu}^{\prime}$ est ce que le territoire? In: Les territoires du quotidien, sous la direction de Guy Di Méo. Paris: L’Harmattan, 1996, p. 17-34.

Recebido em: 23/06/11 Aceito em: 16/09/11 